\title{
A erradicação do trabalho escravo até 2030 e os desafios da vigilância em saúde do trabalhador
}

\author{
Eradicating slave labour by 2030: the challenge of worker health \\ surveillance
}

Luís Henrique da Costa Leão (https://orcid.org/0000-0003-0166-5066) ${ }^{1}$

Penelope Siebert (https://orcid.org/0000-0003-3817-229X) ${ }^{2}$

Alexander Trautrims (https://orcid.org/0000-0001-8428-3682) ${ }^{4}$

Valter Zanin (https://orcid.org/0000-0002-7911-8583) ${ }^{3}$

Kevin Bales (https://orcid.org/0000-0003-1516-7148) ${ }^{4}$

${ }^{1}$ Programa de PósGraduação em Saúde

Coletiva, Universidade Federal do Mato Grosso. Av. Fernando Corrêa da Costa 2367, Boa Esperança. 78060900 Cuiabá MT Brasil. luis_leao@hotmail.com ${ }^{2}$ Nottingham Trent University, Reino Unido.

${ }^{3}$ Departamento de Filosofia, Sociologia, Pedagogia e Psicologia Aplicada, Padova University. Padova Italy.

${ }^{4}$ Rights Lab, Universidade

de Nottingham, Reino

Unido.

\begin{abstract}
Eradicating modern slavery is a relevant scientific, social, and institutional challenge issue. Indeed, efforts are being made globally to understand, map, and eradicate contemporary slavery as a target of the United Nations Sustainable Development Goals by 2030. However, little attention has been given to the Occupational Health Surveillance (VISAT) in the strategies and struggle against exploiting relationships. In order to fill this gap, the paper discusses contemporary slave labor (CSL) and its specificities in Brazil from an occupational health surveillance perspective. We initially highlight the link between CSL, occupational health, and occupational health surveillance (VISAT). We then present three VISAT challenges to addressing CSL: the challenging task of characterizing economic sectors and populations most affected; identifying determinants, risks, and effects on health; and strengthening occupational health practices and services to trigger specific actions regarding formation, information, and intervention in regions of high CSL prevalence. We conclude that Occupational Health Surveillance can play an essential role in the emancipation of workers engaged in slavery relationships.

Key words Slave labor, Modern slavery, Occupational health, Health surveillance, Human trafficking
\end{abstract}

Resumo A erradicação das formas contemporâneas de escravidão é uma relevante questão científica, social e institucional. De fato, esforços globais têm sido feitos para compreender, mapear e eliminar a escravidão contemporânea, como um dos objetivos do Desenvolvimento Sustentável das Nações Unidas até 2030. Entretanto, pouca atenção tem sido dada para o lugar da vigilância em saúde do trabalhador (VISAT) nas estratégias e lutas pela erradicação dessas relações de exploração. Para suprir essa lacuna, este artigo discute o trabalho escravo contemporâneo (TEC) e suas especificidades no Brasil, na perspectiva da VISAT. Inicialmente, destacamos as relações entre trabalho escravo, saúde do/a trabalhador/a e a vigilância em saúde e, em seguida, apresentamos três desafios da vigilância para o enfretamento do TEC: o desafio de caracterizar setores econômicos, regiões e populações afetadas; o de identificar determinantes, riscos e efeitos à saúde; e o de fortalecer práticas e serviços de saúde do trabalhador para desencadear ações de formação, informação e intervenção em regiões de maior presença de TEC. Conclui-se que a vigilância em saúde do trabalhador pode trazer contribuições significativas para emancipação de trabalhadores em contextos de trabalho escravo.

Palavras-chave Trabalho escravo, Escravidão moderna, Saúde do trabalhador, Vigilância em saúde, Tráfico de pessoas 


\section{Introdução}

No século XXI um novo abolicionismo emergiu em um reavivamento do ativismo antiescravidão $0^{1}$. Esforços têm sido realizados em escala global a fim de compreender, mapear e erradicar a escravidão contemporânea, o tráfico humano e o trabalho forçado, como um alvo dos Objetivos do Desenvolvimento Sustentável (SDG 8.7) das Nações Unidas até 2030.

As novas formas de escravidão são fenômenos estruturais do sistema de acumulação econômico global e sua incidência nas diferentes formações sociais pós-abolição formal da escravatura são difíceis de medir comparativamente. Assim, de modo aproximativo, estima-se que o número de pessoas escravizadas atualmente seja de 40,3 milhões ${ }^{2}$. Destaca-se que o movimento antiescravidão opera em escala muito menor que o necessário para abordar o problema e faltam recursos para construir soluções adequadas à magnitude e complexidade do fenômeno.

Esse novo abolicionismo utiliza várias estratégias e envolve muitos atores ${ }^{3-5}$, mas pouca atenção tem sido dada aos saberes e práticas da vigilância em saúde do trabalhador (VISAT) e seu papel na identificação, controle e redução da ocorrência da escravidão e no suporte às vítimas do trabalho escravo contemporâneo (TEC).

Frequentemente, o direito à saúde é negligenciado nas ações antiescravidão, o setor saúde é deixado de fora dos processos políticos decisórios e faltam indicadores dos impactos da escravidão na saúde e ambiente ${ }^{7,8}$. Por isso, criar estratégias de VISAT seria essencial para oferecer mais suportes em prol da meta de erradicar a escravidão. Nesse ponto, há uma limitação na literatura acadêmica internacional, pois ela focaliza principalmente a assistência à saúde das pessoas que foram escravizadas, destacando a importância de aumentar a capacidade clínica, ampliar a formação de profissionais para identificar vítimas nos serviços de saúde ${ }^{9-11}$ e compreender consequências físicas e mentais do trabalho escravo para subsidiar tratamentos adequados ${ }^{12-14}$.

Neste artigo, abordamos o trabalho escravo na perspectiva da VISAT, chamando atenção para alguns desafios no caso do Brasil. Buscamos explicar a conexão entre TEC, saúde do trabalhador e VISAT e discutimos três desafios a partir de dados quantitativos e qualitativos coletados particularmente no estado de Mato Grosso. Esses dados são provenientes do seguro-desemprego especial do Ministério da Economia, do Observatório da Erradicação do Trabalho Escravo e do
Tráfico de Pessoas (SmartLab), dos Centros de Referência em Saúde do Trabalhador (CERESTs) e das narrativas de trabalhadores resgatados. Com base neles problematizamos (1) a questão dos setores econômicos e populações mais afetadas pelo trabalho escravo; (2) os determinantes, riscos e efeitos à saúde relacionados ao TEC; (3) o fortalecimento dos serviços de saúde do trabalhador para desencadear intervenções específicas.

\section{Trabalho escravo, saúde do(a) trabalhador(a) e vigilância}

A relação entre o tema do trabalho escravo e o campo da saúde do(a) trabalhador(a) é um relevante eixo de pesquisa e ação ainda a ser melhor explorado e sistematizado.

Historicamente, desde que os primeiros registros humanos escritos foram gravados em argila em cuneiforme pelos povos sumerianos, houve relatos associando trabalho escravo e más condições de saúde. Obviamente, o nível de saúde-doença de populações escravizadas é conformado pelas características histórico-espaciais da escravidão, tipos de regimes de dominação/ exploração, condições de trabalho específicas nos variados setores (trabalho doméstico, plantações, pecuária, minas, manufaturas, serviços urbanos etc.) e pela oferta/ausência de cuidados médicos, entre outros fatores. Sabe-se que diferenças entre cuidados médicos para escravos e cidadãos livres têm sido gritantes na medida em que, para escravos, houve pouca preocupação com as causas das doenças e o foco das curas estava em consertar seus corpos de modo a possibilitar o retorno às suas atividades ${ }^{15}$.

Durante o período da escravidão colonial Afro-Americana nos séculos XVI-XIX, por exemplo, diversas experiências e práticas de medicina colonial e da nascente saúde pública buscaram sujeitar e controlar populações escravizadas, disciplinar e regular corpos em todas as etapas da escravização, desde a captura de pessoas em terra natal, nos navios do tráfico transatlântico e nos campos de trabalho propriamente ditos ${ }^{16,17}$. Fato merecedor de maior atenção é que esse modelo não foi aceito passivamente. Inclusive, as resistências, revoltas e lutas de grupos escravizados, bem como suas artes de curar praticadas tantas vezes em oposição à medicina colonial escravocrata $^{18}$ talvez possam figurar como as pioneiras expressões da saúde de trabalhadores na história moderna.

É preciso reconhecer ainda que essa escravidão colonial legalizada deixou heranças so- 
cioculturais e psicológicas nas Américas, que se refletem atualmente no racismo e nas iniquidades em saúde, especialmente na subalternização de trabalhadore(a)s negro(a)s, mulheres e nas opressões sobre as comunidades afrodescendentes e periféricas ${ }^{19}$. No Brasil, as próprias relações sociais e as estruturas de empregabilidade atuais têm raízes ancoradas nos legados coloniais e se assentam em desigualdades de classe, raça e gênero, hierarquias políticas e econômicas elitistas, latifúndio e desvalorização de trabalhadore(a)s.

A nosso ver, o trabalho escravo contemporâneo está exatamente conectado ao neocolonialismo, patriarcalismo, racismo e sexismo do desenvolvimento capitalista conformando uma violência estrutural cujos gradientes de exploração expõem discriminações, desigualdades, iniquidades e repercussões na saúde.

Os impactos à saúde decorrentes do TEC, entretanto, precisam ser mais bem compreendi$\operatorname{dos}^{20,21}$. Estudos têm demonstrado doenças crônicas e agudas devido às condições insalubres, riscos e perigos ocupacionais e ambientais dos processos de produção ${ }^{22}$ e sua contribuição na disseminação de doenças infectocontagiosas ${ }^{23}$. Tais impactos ocorrem em diferentes níveis de severidade e afetam aspectos físicos, psicológicos, socioculturais (incluindo as famílias das vítimas) e territoriais devido à degradação ambiental, desmatamentos, uso de agrotóxicos, mineração ilegal dentre outras atividades com base em trabalho escravo que prejudicam a qualidade do ar, solo, acesso à água potável etc ${ }^{21,22}$.

A escravidão contemporânea é um fenômeno multifacetado cujas definições suscitam importantes debates no cenário acadêmico, político, social e institucional. Na literatura internacional, por exemplo, a expressão "escravidão moderna" tem sido utilizada enquanto termo guarda-chuva para cobrir variadas formas de exploração como trabalho forçado, tráfico humano, exploração sexual, trabalho infantil, servidão por dívidas e outras práticas análogas.

Não há espaço aqui para recompor uma análise abrangente e crítica de todo o debate nas ciências sociais, econômicas e jurídicas em torno dessas categorias, mas convém explicitar que o modo de caracterizar esse fenômeno pode ampliar ou restringir o leque de opções para a emancipação de trabalhadores.

Aportes da economia política marxista, por exemplo, sob a rubrica do conceito de trabalho não-livre ${ }^{24}$ ampliam o olhar para descrever expropriações e explorações capazes de cobrir variadas formas autoritárias de controle e meca- nismos de coerção imobilizadores da classe trabalhadora.

Em uma perspectiva antropológica, Patterson $^{25}$ trouxe importantes avanços ao conceituar a escravidão como uma relação de poder e dominação que envolve dimensões culturais, psicológicas e sociais, interconectando violência, alienação genealógica e desonra/indignidade social. A escravidão poderia ser compreendida assim como uma experiência de "morte social"25.

Estudos clássicos como o de Elkins ${ }^{26}$, apontam inclusive similaridades entre as realidades da escravidão e dos campos de concentração, como instituições cuja brutalidade leva à dissolução de personalidades e ao desenvolvimento de um tipo de infantilização e dependência psicológica.

De outros pontos de vista, autores ressaltam três aspectos comuns definidores do trabalho compulsório, servidão por dívida, exploração sexual infantil e prostituição forçada: perda da possibilidade de exercício da livre vontade, apropriação da força de trabalho e uso da violência ${ }^{5,22}$.

Neste artigo, escolhemos utilizar o termo trabalho escravo contemporâneo para destacar que estamos tratando de relações de trabalho específicas e para seguir a definição legal brasileira na qual nossos dados estão baseados. Destaca-se que essa definição é uma das mais avançadas pela sua abrangência, uma vez que ela não restringe o TEC às privações da liberdade, mas conceitua-o também como negação da dignidade de trabalhadore(a)s. Ela ressalta que não se trata de uma condição permanente (escravo como um atributo da pessoa), mas um contexto de opressão, exploração e violência situacionais caracterizados por quatro componentes (concomitantes ou não): condições degradantes, jornadas exaustivas, servidão por dívida e/ou trabalho forçado ${ }^{27}$.

A vigilância dessas condições de trabalho degradantes, exaustivas e em contextos de endividamento e coerções dos trabalhadores se caracteriza não por ações pontuais de "resgate", mas práticas contínuas, complexas, sistemáticas e participativas, cujo horizonte é o desmantelamento gradativo das possiblidades de reprodução social dessas formas de exploração. Prevenir e controlar riscos e agravos ambientais e ocupacionais para mudar o quadro de desalento, esgotamento, desgastes físicos e mentais em situações e contextos de TEC requer intervenções de múltiplos níveis e agentes. Tal vigilância não se restringe ao monitoramento de doenças, acidentes e mortes relacionadas ao $\mathrm{TEC}^{28}$, mas incorpora a análise da magnitude e severidade dos casos, a identificação de áreas geográficas, setores e ocupações impactadas, o ma- 
peamento da distribuição dos casos e seus respectivos riscos para desenvolver estratégias concretas de rompimento dos ciclos de escravização. Para isso, a VISAT busca reunir movimentos sociais, setores públicos, organizações não-governamentais e os trabalhadores organizados como agentes fundamentais, se ancorando em diferentes fontes de conhecimento - popular e científico - para reduzir agravos e promover saúde ${ }^{28}$.

Embora poucos estudos abordem práticas e experiências da VISAT frente à escravidão contemporânea, chama atenção que a Comissão dos Determinantes Sociais da Saúde da Organização Mundial da Saúde tenha incluído a escravidão/ trabalho servil entre as categorias prioritárias para o enfrentamento das iniquidades em saúde em nível global, ressaltando a necessidade de detectar populações afetadas, monitorar as desigualdades e identificar potenciais intervenções ${ }^{7}$. Esse olhar mais amplo da Saúde Pública, inclusive, é capaz de contribuir para superar limitações das abordagens jurídicas e punitivas do combate ao tráfico humano ${ }^{29}$, pela identificação de fatores de risco e pela criação e avaliação de programas preventivos, que considerem as particularidades de cada estágio do processo de tráfico - recrutamento, transporte, exploração, detenção, integração-reintegração e reescravização ${ }^{30}$. Com base nessa fundamentação, a seguir, destacamos três desafios da VISAT frente a demanda pela erradicação do TEC.

\section{O desafio de caracterizar setores econômicos e populações afetadas pelo TEC}

Um desafio da VISAT ao abordar o TEC é melhorar a compreensão e monitoramento dos setores econômicos, processos produtivos, características geográficas e populações afetadas pelo trabalho escravo. No Brasil, de acordo com dados do Ministério Público do Trabalho/Ministério da Economia $^{31}, 45.028$ trabalhadores foram resgatados de trabalho escravo entre 2003 e 2018 . A maior parte desses resgates $(90,4 \%)$ ocorreu no setor primário da economia, na agricultura ${ }^{31} \mathrm{e}$ maior proporção desses casos foi encontrada nos estados do Pará (24,7\%) e Mato Grosso (11,4\%). Dados de 35.682 trabalhadores resgatados que receberam seguro desemprego especial entre 2003 e março de 2018, mostram que maior proporção envolveu homens (95\%), solteiros, com baixo nível de escolaridade, em ocupações como trabalhador geral da agricultura, trabalhador da construção, da agropecuária, pedreiro e trabalhador rural (Tabela 1).
Em Mato Grosso, 4.394 trabalhadores foram resgatados e 1.799 foram incluídos no seguro desemprego especial. Este perfil segue o padrão nacional, envolvendo mais homens, (96\%), com pouca escolaridade ( $28 \%$ analfabetos e $41 \%$ estudaram até o $5^{\circ}$ ano incompleto), $13 \%$ deles eram mestiços e trabalhadores gerais da agricultura (77\%), operadores de motosserra (4\%) e trabalhadores rurais $(4 \%)$.

Esses dados dão uma ideia sobre setores, atividades econômicas e perfil de escravizados no Brasil, mas são restritos aos casos reportados pela inspeção do trabalho que não abrangem todas as situações de escravidão (por exemplo, a escravização no comércio de exploração sexual está geralmente fora da ação habitual da fiscalização). Como resultado, a VISAT tem o desafio de produzir outras informações qualitativas e quantitativas que requerem novas métricas, estatísticas e estimativas, porque a população afetada e os padrões de exploração em vários setores econômicos e regiões brasileiras muito provavelmente sejam maiores e mais complexos que os dados acessíveis sugerem.

Existe uma grande e invisível população explorada em diferentes atividades econômicas, territórios e processos de produção, submetida a condições cujos parâmetros equivalem às classificações de trabalho escravo. Os dados disponíveis não necessariamente cobrem situações como: o trabalho forçado de crianças e adolescentes sob o controle de gangs criminosas e traficantes de drogas; meninas e mulheres de regiões mais podres "dadas" por suas famílias para trabalhar em serviços domésticos não remunerados; mulheres e meninas exploradas sexualmente e traficadas para o exterior sob falsas promessas; e eventual trabalho forçado no sistema penitenciário; entre outras situações consideradas como explorações "normais" às quais caberiam a definição de TEC. Até o momento, o que é conhecido sobre trabalho escravo cobre uma fração muito pequena de uma mais ampla, complexa e diversa realidade.

Os dados aqui descritos indicaram que o TEC no Brasil envolveu mais homem em idade produtiva e em situações de vulnerabilidade. Do ponto de vista internacional, a maioria das vítimas da escravidão é composta por mulheres, em grande parte devido ao tráfico para exploração sexual comercial e pelo trabalho doméstico ${ }^{3,20}$. É importante conectar isso com a legislação brasileira a qual não criminaliza exploração sexual comercial, levando a uma relativa invisibilidade da mulher (e homens e crianças) que pode ser escravizada nessas atividades. Comparado a ou- 
Tabela 1. Caraterísticas demográficas e socioeconômicas de trabalhadores resgatados do trabalho escravo no Brasil e em Mato Grosso, 2003-2018.

\begin{tabular}{|c|c|c|c|c|c|}
\hline & \multicolumn{2}{|c|}{ Brasil } & & \multicolumn{2}{|c|}{ Mato Grosso } \\
\hline & $\mathbf{N}$ & $\%$ & & $\mathbf{N}$ & $\%$ \\
\hline Estado Civil & & & Estado Civil & & \\
\hline Solteiros & 12.520 & $(35)$ & Solteiros & 451 & (25) \\
\hline Casados & 5.453 & (15) & Casados & 300 & (17) \\
\hline Ignorado & 3.756 & (11) & Ignorado & 215 & (12) \\
\hline Outros & 13.953 & (39) & Outros & 833 & (46) \\
\hline Total & 35.682 & $(100)$ & Total & 1.799 & $(100)$ \\
\hline Sexo & & & Sexo & & \\
\hline Masculino & 33.682 & (95) & Masculino & 1.734 & (96) \\
\hline Feminino & 1.824 & (5) & Feminino & 65 & (4) \\
\hline Total & 35.682 & $(100)$ & Total & 1.799 & $(100)$ \\
\hline Escolaridade & & & Escolaridade & & \\
\hline Analfabeto & 11.115 & $(31)$ & Analfabeto & 500 & (28) \\
\hline Até $5^{\circ}$ ano inc. & 13.573 & $(38)$ & Até $5^{\circ}$ ano inc. & 736 & (41) \\
\hline $5^{\circ}$ ano completo & 1.349 & (4) & $5^{\circ}$ ano completo & 55 & (3) \\
\hline Até o $9^{\circ}$ ano inc. & 5.323 & (15) & Até o $9^{\circ}$ ano inc. & 320 & (18) \\
\hline Fundamental Comp. & 1.514 & $(4)$ & Fundamental Comp. & 67 & (4) \\
\hline Ensino Médio inc. & 941 & (3) & Ensino Médio inc. & 37 & (2) \\
\hline Ensino Médio comp & 939 & (3) & Ensino Médio comp & 33 & (2) \\
\hline $3^{\circ}$ grau incompleto & 38 & $(0)$ & $3^{\circ}$ grau incompleto & 3 & (0) \\
\hline $3^{\circ}$ grau completo & 13 & $(0)$ & $3^{\circ}$ grau completo & 0 & (0) \\
\hline Sem resposta & 877 & (2) & Sem resposta & 48 & (3) \\
\hline Total & 35.682 & $(100)$ & Total & 1.799 & $(100)$ \\
\hline Cor & & & Cor & & \\
\hline Mulata, Cabocla, Cafuza, Mam. Mestiça & 5057 & (14) & $\begin{array}{l}\text { Mulata, Cabocla, Cafuza, Mam. } \\
\text { Mestiça }\end{array}$ & 232 & (13) \\
\hline Branca & 3.021 & $(8)$ & Branca & 128 & (7) \\
\hline Preta & 1.474 & (4) & Preta & 98 & (5) \\
\hline Indígena & 481 & (1) & Indígena & 2 & (0) \\
\hline Amarelo & 2.461 & (7) & Amarelo & 125 & (7) \\
\hline Ignorado & 23.188 & $(65)$ & Ignorado & 1.214 & (67) \\
\hline Total & 35.682 & $(100)$ & Total & 1.799 & $(100)$ \\
\hline Ocupação & & & Ocupação & & \\
\hline Trab. geral agricultura & 26.601 & $(75)$ & Trab. geral agricultura & 1.377 & (77) \\
\hline Trab. construção & 1.399 & (4) & Trab. construção & 32 & (2) \\
\hline Trab. pecuária & 913 & (3) & Trab. pecuária & 33 & (2) \\
\hline Pedreiro & 823 & (2) & Pedreiro & 24 & (1) \\
\hline Trab.cana-de-açúcar & 767 & (2) & Trab.cana-de-açúcar & 1 & (0) \\
\hline Trab. rural & 646 & (2) & Trab. rural & 74 & (4) \\
\hline Trab. mineração & 627 & (2) & Trab. mineração & 1 & (0) \\
\hline Operador motosserra & 418 & (1) & Operador motosserra & 70 & (4) \\
\hline Outros & 3.488 & (10) & Outros & 187 & (10) \\
\hline Total & 35.682 & $(100)$ & Total & 1.799 & $(100)$ \\
\hline
\end{tabular}

tras jurisdições, sabemos pouco sobre o tamanho e forma da escravização no comércio da exploração sexual. Embora menos se saiba sobre este tipo de escravidão no Brasil, está claro, a partir de dados globais, que tal escravidão acarreta significativos riscos à saúde. Claramente, usar uma estrutura padronizada para identificar e classificar as características sociodemográficas e de saú- 
de de escravizado(a)s é um trabalho importante para as instituições de saúde.

Neste sentido, as atuais transformações no cenário econômico, incluindo os impactos da pandemia do COVID-19 são temas merecedores da atenção da VISAT para reforçar seus mecanismos de ação em setores com alta ocorrência de casos de TEC.

Em muitas partes do mundo, o TEC está altamente concentrado na agricultura, construção civil, indústrias de manufatura e mineração, assim como em trabalho doméstico e na comercialização sexual ${ }^{33}$. Portanto, o TEC ocorre em processos produtivos de uma ampla gama de mercadorias como açúcar, chá, óleo de palma, carne, algodão, metais, eletrônicos, vesturário e na oferta de serviços ${ }^{32}$. Então, uma importante estratégia é organizar ações de VISAT nas e ao longo das cadeias produtivas para monitorar as condições de trabalho e riscos ocupacionais no processo de trabalho por trás dos produtos, mercadorias e bens que circulam no mercado.

Como o TEC é um problema global, são necessários mais esforços nessa direção, para ampliar mecanismos de controle de cadeias produtivas articulando organizações como a OMS e OIT, favorecendo o monitoramento da saúde e das condições de trabalho em setores econômicos prioritários. Esta tarefa vai além da responsabilidade das companhias e setores privados envolvidos no monitoramento dos riscos de escravidão nas cadeias de fornecimento. $\mathrm{O}$ modelo de intervenção de gestão dos negócios para combater a escravidã $0^{4}$, por exemplo, geralmente envolve mapeamento de fornecedores, inspeção de auditorias e regimes éticos de certificação. Entretanto, essa abordagem tem limites e lacunas de governança, pois falham em detectar e corrigir relações de trabalho em determinados elos da cadeia ${ }^{34}$. Além dessas formas de governança dirigidas pelas empresas, as alianças entre saúde pública, sindicatos, ONGs, movimentos e outros atores sociais tem potencial de melhor identificar e controlar impactos à saúde e ambiente em cadeias produtivas com alta presença de $\mathrm{TEC}^{35}$.

\section{$O$ desafio de identificar determinantes, riscos e efeitos à saúde relacionados ao TEC}

Outro importante desafio para a VISAT é reconhecer determinantes sociais, riscos ocupacionais e efeitos do trabalho escravo na saúde. No Brasil, ainda não existem indicadores oficiais relativos à determinantes, riscos e problemas de saúde relacionados às diferentes formas, condições e experi- ências de escravidão. Devido a essa lacuna, exploramos alguns dados qualitativos de trabalhadores e movimentos sociais no estado de Mato Grosso, coletados entre 2018 e 2019, no contexto do Projeto Ação Integrada, cujo objetivo é oferecer suporte aos resgatados do trabalho escravo no estado. Durante as atividades do projeto foi possível tomar conhecimento de testemunhos e narrativas de experiências vividas na escravidão e informações de movimentos sociais que fornecem uma visão geral sobre: (a) aspectos da natureza do TEC em Mato Grosso, as características, condições, atividades e tarefas daqueles que foram submetidos à escravidão; (b) o contexto anterior e posterior ao resgate de trabalhadores; (c) exemplos de ações e estratégias de combate ao TEC; e (d) sinais e sintomas de problemas de saúde e possíveis adoecimentos. Esses dados permitem entender melhor o tipo de escravidão, as formas de exploração, a exposição a riscos, os danos referidos e os agravos pela ótica dos trabalhadores.

Essas informações demonstram que o TEC envolve três conjuntos de situações críticas geradoras de agravos físicos, psicossociais e psicológicos: violência extrema, severa exploração e péssimas condições de reestabelecimento das forças.

As violências se dão pela vigilância constante e acirrada, abusos físicos, coerção, manipulação, supervisão armada, controle e restrição da liberdade (incluindo privação forçada de sono), má nutrição, ameaças psicológicas e punições corporais. Os trabalhadores experimentam extrema exploração, caracterizada por formas perigosas de transporte, jornadas longas e exaustivas - mais de 12 horas por dia em alguns casos - horários de trabalho não definidos, falta ou irregularidade no pagamento. Essas situações abrangem tanto os trabalhadores locais, quanto os migrantes, e, às vezes, é de duração relativamente curta.

Geralmente, migrantes são recrutados em regiões mais pobres e vão ou são levados ao Mato Grosso. Quando chegam, são isolados, frequentemente alojados em precárias condições em distritos rurais. Eles são levados a florestas ou fazendas sob falsas promessas de que haverá rápidos e fáceis ganhos financeiros. Entretanto, a realidade é bem diferente e eles realizam muitas tarefas intensas e exaustivas que demandam força física e alto nível de gasto energético, normalmente em atividades árduas e de pouca qualificação, sem pausas ou oportunidades de descanso. É evidente que não existe treinamento de saúde e segurança nesse ambiente de trabalho e o retorno financeiro (quando recebem) em geral não atinge o valor de um salário mínimo. 
Quando o trabalhador é atraído para uma área remota e obtém-se controle sobre sua pessoa, esse controle pode-se efetivar através de aplicação de dívidas falsas. Isso envolve "cobranças" pela comida que comem, ferramentas que usam e pelos custos de transporte. Tais "taxas" são normalmente superfaturadas pelo "empregador". Esse controle e exploração são comuns ao longo da cadeia do agronegócio, em fazendas ou florestas, geralmente em tarefas como limpar terreno, fazer cercas, cortar madeiras e árvores, alimentar gado ou abatê-lo para produzir carne.

Nesse contexto, trabalhadores são expostos a diferentes tipos de riscos: biológicos (fungos, bactérias, vírus) tanto nos alojamentos quanto no ambiente de trabalho; físicos (insetos, répteis e outros animais perigosos e transmissores de doenças, radiação solar, e equipamentos antigos e perigosos), químicos (dormir no mesmo local de armazenamento de agrotóxicos e combustíveis), e ergonômicos (máquinas e ferramentas pesadas, movimentos repetitivos, carga de trabalho intensa etc). Além disso, os trabalhadores são sujeitos às situações estressantes, cenários degradantes, más condições de vida e higiene, isolamento, retenção de documentos, água inadequada e péssimos alojamentos. Em caso de acidentes ou adoecimentos, há pouca possibilidade de buscar serviços de saúde ou cuidados médico-hospitalares devido ao controle exercido pelos "chefes" e pelo isolamento geográfico.

Então, o TEC combina (a) condições e características de atividades em situações críticas (exposição a riscos ocupacionais e ambientais, condições de trabalho extremas e jornadas exaustivas etc.), (b) presença de formas severas de controle e violência (psicológica, física, negligências etc); e (c) más condições de reprodução (alojamentos, alimentação, vestuário, água, locomoção/ transporte etc). O TEC, portanto, é um processo de imposição de situações de alto potencial para causar doenças, acidentes e uma ampla gama de sofrimentos.

Nos relatos de trabalhadores é possível identificar graves impactos à sua saúde. Nas dimensões físicas, por exemplo, há menção a doenças e condições decorrentes do processo de trabalho, contexto ambiental, pressões e violências do TEC, como malária, febres, problemas respiratórios, diarreia, inflamações, danos musculares, cegueira, entre outros. Isso demonstra claramente o quanto o TEC forja corpos danificados e enfraquecidos, muitas vezes levados à exaustão. A ameaça à vida se revela constante e até casos de assassinatos são reportados.
Em um quadro dramático como esse, diversas consequências psicossociais e psicológicas despontam nas narrativas de resgatados, como a sensação de abandono e solidão devido às quebras dos laços familiares, alto grau de desvalorização e desumanização (sentimento de ser tratado como um animal), uso de álcool devido às pressões desse contexto, além de manifestações de sentimentos e reações como medos, raiva, tristezas, agressividade, ansiedade, entre outros, podendo culminar também em traumas e transtornos de estresse pós-traumático (Quadro 1).

Os trabalhadores relatam ainda vários riscos e vulnerabilidades como indutores e determinantes sociais para a situação de escravização. A maioria dos ex-escravizados sofreu abusos na família, vivenciou trabalho infantil, abandonos parentais, pobreza e acesso limitado à escola, moradia, alimentação e cuidados médicos. Suas histórias de vida são plenas de menções à discriminações, racismo e desvantagens socioculturais que trazem sentimentos de menor valia e visão de si mesmos como "sub-cidadãos" ou mesmo uma "coisa".

Vários estudos apontam que grupos sociais pobres e discriminados se tornam vulneráveis ao TEC e que o aumento da pobreza, destruição ambiental, corrupção, crises socioeconômicas, conflitos e violências são fatores que pressionam na direção dessas formas de exploração ${ }^{5,30,34,12}$. Políticas de redução da pobreza e corrupção, e de melhoria no acesso à educação, emprego, renda e moradia são impulsionadores-chave no combate ao TEC. Mesmo assim, mais pesquisas precisam ser feitas para investigar os principais fatores estruturais, sociais e individuais que levam à exploração ${ }^{20}$ e suas interações com os determinantes sociais do status da saúde-doença das populações ${ }^{7}$.

Está claro que o TEC tipifica uma situação perigosa de alta probabilidade de causar danos, porque envolve um ciclo de geração e exposição a ameaças ambientais e ocupacionais à saúde e às violações dos direitos humanos. De acordo com Zimmerman e Kiss ${ }^{20}$, inclusive, esses três elementos, coerção, exploração e danos à saúde, estão todos conectados nos casos de escravidão contemporânea.

Isso significa que o TEC pode ser entendido não apenas como a perda da liberdade, mas também como o oposto da saúde. Saúde não é ausência de doenças, mas boas condições que fazem a vida ser possível, como alimentação, abrigo, renda, trabalho, transporte, acesso a serviços de saúde etc. Todos esses elementos estão ausentes, são negligenciados ou estão fora do controle dos trabalhadores escravizados. 
Quadro 1. Aspectos percebidos relacionados aos determinantes, riscos e efeitos para a saúde decorrentes do trabalho escravo.

\begin{tabular}{|c|c|c|}
\hline Determinantes & Riscos & Efeitos à saúde \\
\hline $\begin{array}{l}\text { História de trabalho infantil, } \\
\text { exploração, abandono e violência } \\
\text { Famílias em situação vulnerável } \\
\text { Barreiras ao acesso às instituições } \\
\text { de ensino }\end{array}$ & $\begin{array}{l}\text { Violência } \\
\text { Vigilância constante, abusos } \\
\text { corporais, coerção, manipulação, } \\
\text { formas de punição, controle } \\
\text { de comportamento, estratégias } \\
\text { de dominação e privação de } \\
\text { liberdade, violência psicológica, } \\
\text { física e negligências }\end{array}$ & $\begin{array}{l}\text { Físico } \\
\text { Malária, febre, acidentes e incidentes } \\
\text { de trabalho, problemas respiratórios, } \\
\text { sinais de desgaste, diarreia, } \\
\text { assassinatos, cegueira, exaustão, } \\
\text { cansaços }\end{array}$ \\
\hline $\begin{array}{l}\text { Necessidade de alimentar e } \\
\text { sustentar a família }\end{array}$ & $\begin{array}{l}\text { Exploração severa } \\
\text { Condições de trabalho }\end{array}$ & Psicossocial \\
\hline $\begin{array}{l}\text { Fraquezas na execução de } \\
\text { políticas públicas de inclusão, } \\
\text { educação, emprego, renda etc } \\
\text { Incentivos governamentais em } \\
\text { cadeias de commodities focadas } \\
\text { em nível econômico apenas }\end{array}$ & $\begin{array}{l}\text { inadequadas, longas horas de } \\
\text { trabalho, exposição a riscos } \\
\text { ocupacionais e ambientais, } \\
\text { Falta de planos e estratégias de } \\
\text { saúde e segurança no trabalho, } \\
\text { baixa remuneração ou ausência de } \\
\text { pagamentos, controles armados e } \\
\text { supervisão }\end{array}$ & $\begin{array}{l}\text { Uso de álcool e outras drogas, } \\
\text { isolamento das redes e laços } \\
\text { familiares, sensação de perda de } \\
\text { tempo e oportunidades, humilhação e } \\
\text { sensação de pouco valor } \\
\text { Psicológico }\end{array}$ \\
\hline $\begin{array}{l}\text { Desigualdade e falta de } \\
\text { oportunidade } \\
\text { Políticas de desenvolvimento } \\
\text { econômico insustentáveis }\end{array}$ & $\begin{array}{l}\text { Condições precárias de vida } \\
\text { Isolamento (dificuldade de } \\
\text { coletivizar demandas), má } \\
\text { nutrição, água suja, acesso escasso } \\
\text { a serviços de saúde, abrigo em } \\
\text { condições inadequadas, confisco } \\
\text { de documentos, falta de assistência } \\
\text { médica e sanitária etc }\end{array}$ & $\begin{array}{l}\text { Tristeza, ansiedade, raiva, medo, } \\
\text { agressividade, preocupação com o } \\
\text { futuro }\end{array}$ \\
\hline
\end{tabular}

Fonte: Autores, baseado em entrevistas realizadas em Mato Grosso com trabalhadores resgatados e movimentos sociais entre 20182019 e experiência do Projeto Ação Integrada que oferece suporte para esses trabalhadores.

Mais ainda, se saúde é a capacidade de cada grupo social controlar esses elementos-chave ${ }^{36}$, então, a falta de controle e acesso a esses elementos demonstra o alto nível de risco que o TEC representa. A literatura acadêmica, inclusive, demonstra vários riscos e efeitos à saúde similares aos nossos resultados ${ }^{9,10,37}$.

Em termos de saúde mental, de acordo com duas diferentes teorias - psicodinâmica do trabalho $^{38}$ e modelo demanda-controle ${ }^{39}$ - falta de controle e autonomia dos trabalhadores sobre suas atividades, movimentos, processo de trabalho, horário de trabalho, relações hierárquicas e organização do trabalho rígida, podem levar a altos índices de estresse ou sofrimentos patogênicos causadores de efeitos corporais e psíquicos. A esse respeito, depressão, ansiedade e estrese póstraumático são comumente citados como efeitos da escravização $0^{10,13,14}$. Além do mais, o TEC é uma profunda experiência de sofrimento social impactando dimensões físicas, psicossociais e psicológicas dos trabalhadores. A escravidão representa um ataque frontal ao direito de trabalhadores à saúde. Então, a VISAT é uma alternativa para abordar, melhor compreender e intervir nas causas raízes dessa forma de sofrimento social $^{7}$ moldada por contextos socioambientais que interconectam cooptação/coerção de populações negligenciadas, em situações de pobreza e com pouco acesso à terra em cenários de autoritarismos, mandonismos e violências associados a processos de desenvolvimento injustos que destroem saberes, tradições locais e potencialidades pessoais. O TEC, portanto, está associado à redução de possibilidades de vida e às situações cerceadoras da existência material-corporal, porque se revela como consumo acelerado das energias de trabalhadores, capaz de induzir ao esfacelamento de seus potenciais físicos e mentais. 


\section{O desafio de fortalecer serviços para desencadear intervenções específicas}

Outro desafio relevante que destacamos é o necessário fortalecimento dos serviços/ações de saúde do trabalhador no SUS e a ampliação das práticas ético-políticas para prevenir, proteger e promover a saúde de trabalhador(a)s em contextos de escravização.

À luz das experiências brasileiras de combate ao trabalho escravo, seria estratégico: (a) ampliar as capacidades de identificação de casos de trabalho escravo nos pontos de entrada do SUS; (b) expandir a rede de cuidados médicos e psicossociais às vítimas; (c) promover ações visando reduzir riscos de (re)escravização, articulando intervenções, informação e formação.

Um primeiro elemento a considerar é a presença de serviços articuladores de saúde do trabalhador nas regiões com registros de trabalho escravo, indicando assim uma base potencial para maior participação do setor em redes de enfrentamento ao TEC. Por exemplo, ao mapearmos a localização de cada Centro de Referência em Saúde do Trabalhador (CEREST) e a distribuição espacial dos municípios brasileiros com mais de vinte trabalhadores resgatados do TEC, notamos que $67 \%$ dessas cidades estão na área de cobertura dos CERESTs (Figura 1$)^{31}$. Inclusive, dos cinco municípios que concentraram $13,53 \%$ de todos os trabalhadores libertos (Confresa, Ulianópolis, Brasilândia, Campos dos Goytacazes e São Desiderio), dois têm CEREST sede.

A despeito dos limites dos CERESTs e dos problemas estruturais da própria rede de saúde no Brasil, existem caminhos possíveis para organizar planos operacionais frente ao TEC, considerando três temporalidades: antes, durante e depois dos casos.

As possibilidades de ações anteriores à ocorrência da escravidão dizem respeito aos meios para prevenir sua reprodução social, ao incidir sobre seus determinantes através de uma vigilância territorial atenta às populações tradicionais e comunidades vulnerabilizadas (ex. quilombolas, indígenas, camponeses, pescadores, ribeirinhos, assentados etc.), especialmente em cenários de conflitos socioecológicos, atuação de grandes cadeias produtivas, migração sazonal etc. Isso significa agir considerando as raízes e fatores impulsionadores do TEC (altos índices de pobreza, desigualdades, discriminações, racismos, históricos de exclusão, pressões sobre populações tradicionais, migrantes etc.) para reduzir o grau de vulnerabilidade, inibir facilitadores do alicia-

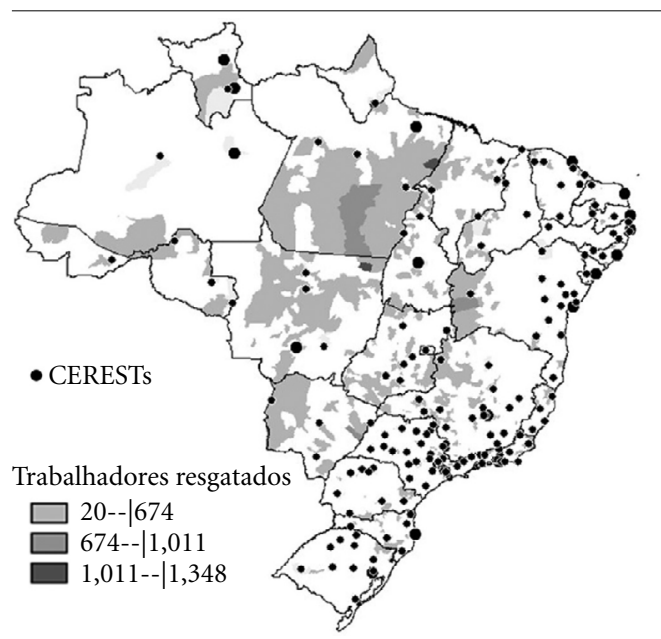

Figura 1. Municípios com trabalhadores resgatados (2003-2018) e distribuição dos CERESTs no território brasileiro (2018)

Fonte: Localização Geográfica dos Cerests conforme dados da Renast-Online existentes em 2018; dados do SmartLab sobre resgate de trabalhadores em território brasileiro entre 20032018 .

mento/tráfico e buscar desenvolver alternativas saudáveis e sustentáveis de trabalho e vida dentro dos próprios territórios, resguardando culturas, saberes, potenciais, habilidades, capacidades e vocações locais. Aqui ganha relevo a vigilância enquanto articuladora de experiências de economia solidária, agroecologia, arranjos produtivos locais, redes de trabalho justo, apoio à agricultura familiar, proteção de territórios e povos tradicionais aliados às políticas sociais e de renda.

Essa vigilância visa desenvolver territórios livres de escravidão com planos intersetoriais e participativos construídos em alianças e colaboração entre serviços de saúde (CERESTs, Agentes Comunitários de Saúde, entre outros, que têm conhecimento em profundidade sobre a realidade local), comunidades e trabalhadores vulneráveis, sociedade civil organizada, movimentos sociais e ONGs levando em conta as características e dinâmicas socioeconômicas ali predominantes. A integração do tema nas pautas do Controle Social - Conselhos de Saúde, Conselhos Estaduais de Erradicação do Trabalho Escravo, Fóruns de Direitos Humanos - amplia as possibilidades concretas de construção de planos e programas locais nesse sentido.

Já o cenário de intervenção durante os casos se refere aos esforços para detectar casos e reprimir o uso de trabalho escravo, delimitando possíveis 
pontos de entrada e de reconhecimento de situações de escravização pelos serviços de saúde, especialmente rede de urgência e emergência, hospitais, unidades de saúde da família, vigilância sanitária etc. O setor e profissionais de saúde têm oportunidades de identificar rapidamente formas de servidão, trabalho forçado, violências, condições degradantes e jornadas exaustivas durante as práticas rotineiras de cuidado/vigilância e em interação com usuários de serviços, migrantes, trabalhadores e trabalhadoras precarizados, atentando para onde eles vivem e trabalham, o que fazem e em que condições. A Vigilância, em conexão com a Atenção Básica é crucial aqui, dado o grau de conhecimento peculiar que suas equipes possuem para descortinar casos suspeitos, gerar informação e subsidiar investigações.

Do ponto de vista da inspeção-fiscalização de ambientes e processos de trabalho, o setor saúde pode oferecer relevantes contribuições ao participar de processos de intervenção colaborativos, junto a outros atores a exemplo de auditores fiscais, da Comissão Pastoral da Terra, do Ministério Público do Trabalho e de organizações de trabalhadores com maior experiência em fiscalização de denúncias de trabalho escravo. As práticas de intervenção interdisciplinar, com equipes amplas e múltiplas - guardadas as competências legais de cada ente - elevam a capacidade investigativa para melhor caracterizar riscos e efeitos à saúde do(a)s trabalhadore(a)s, constatar condições degradantes, perceber elementos constitutivos de jornada exaustiva, servidão e coerção, além de ofertar suportes e encaminhamentos necessários para a atenção clínica e psicossocial resguardando o direito à saúde do(a)s resgatado(a)s.

Nesse último quesito, mais passos precisam ser dados para romper o desamparo dos trabalhadores que são resgatados nas fiscalizações, pois ainda não existe uma linha de cuidados integral, diretrizes e práticas consolidadas de acolhimento, escuta, atenção e reinserção social a esses trabalhadores num fluxo de rede intersetorial junto à assistência social, educação e demais setores pertinentes ao redor do país.

Essa esfera de ação após a ocorrência dos casos se refere ao fortalecimento de experiências de cuidados em saúde, oportunidades de recuperação física e psicossocial conforme as necessidades, sintomas e realidades específicas das vítimas. Isso porque as populações em escravização devem ser visibilizadas e reconhecidas enquanto grupo específico com necessidades de saúde particulares.

Faz-se necessário superar enfoques reducionistas centrados nas doenças e traumas da es- cravidão e restritas ao indivíduo compreendido de modo isolado e desvinculado da realidade sociocultural, ecológica, comunitária e estrutural. Abordagens psicossociais, socioculturais e coletivas mais amplas podem direcionar serviços e profissionais de saúde ao diálogo social com iniciativas como os Projetos Ação Integrada e Rede de Ação Integrada para Combater a Escravidão e outros projetos semelhantes que apoiam trabalhadores libertos da escravidão e vítimas de exploração laboral-sexual para acessar cuidados, superar sujeições e evitar reescravizações. Para isso, se faz necessário criar condições de expansão da autonomia e aumentar as oportunidades para que trabalhadore(a)s retirados de relações de escravidão tenham autonomia, agência econômico-política e, inclusive, tenham suas vozes e conhecimento reconhecidos como imprescindíveis para a melhoria de todo o ciclo de vigilância do TEC. Trabalhador(a)es libert(a)os são atores fundamentais para auxiliar na elaboração e execução de planos de prevenção, fiscalização de processos de trabalho, promoção e atenção à saúde. Seus saberes são capazes de indicar caminhos e gerar informações relevantes sobre razões, consequências e caminhos de libertação dos ciclos do TEC.

Sob o ângulo das informações, a vigilância já tem à disposição diversas fontes importantes dentro e fora do setor saúde (mapeamentos, dados, informações), como o Observatório da Erradicação do Trabalho Escravo e do Tráfico de Pessoas ${ }^{31}$, além de fontes das abordagens nas comunidades e dados de movimentos sociais do território, especialmente, dados da Comissão Pastoral da Terra e ONGs como a Repórter Brasil. Entretanto, no sentido da informação de vigilância epidemiológica e notificação das morbimortalidades causadas pelos tipos de exploração e violência do TEC, se faz necessário melhorar registros e protocolos capazes de auxiliar equipes de saúde nesse processo. Ressalta-se a necessidade de ampliar os mecanismos de notificação de casos de violência, a exemplo do uso da Ficha de Notificação de violência Interpessoal/Autoprovocada do Sistema de Informação de Agravos de Notificação (Sinan) que já contém campos referentes ao trabalho escravo.

Do ponto de vista da formação, destaca-se que o TEC não é uma temática geralmente abordada no currículo tradicional da educação em saúde. O setor de saúde pode suprir essa lacuna organizando cursos e treinamentos para conscientizar o público e os profissionais de saúde a respeito desse crime e buscar formas de melhorar 
as competências, habilidades e capacidades do Sistema de Saúde, em parceria com sindicatos, trabalhadores e comunidades vulneráveis. $\mathrm{Mu}$ nicípios com maior prevalência podem ser priorizados na oferta dessas formações, ao mesmo tempo, ser piloto na assistência às vítimas e em campanhas de saúde pública.

Claro que o desafio de erradicar a escravidão vai além de questões técnicas e instrumentais, pois demanda lutas sociopolíticas necessárias para sustentar caminhos viáveis de emancipação concreta dos trabalhadores nas correlações de forças e dominações existentes nessas formas de exploração (trabalho forçado, escravidão sexual, servidão doméstica etc). Superar o trabalho escravo e mitigar seu impacto à saúde, como problema estrutural, requer levar em consideração suas raízes nas relações econômicas, culturais e sociais, especialmente no Brasil, uma nação nascida sob colonização, genocídio e diferentes formas de escravidão.

Considerando a VISAT em seu caráter emancipatório, tamanhos desafios colocados pelas complexidades do TEC requerem renovadas estratégias protagonizadas pela classe trabalhadora, em sua capacidade de organização e resistência, já que em hipótese alguma deveriam ser figuradas enquanto vítimas passivas, sujeitadas, dominadas e incapazes de autonomia e emancipação. Quebrar esses sistemas de dominação demandam formas de solidariedade entre diferentes estratos de trabalhadore(a)s, para associar ex-escravizado(a)s e aqueles formalmente livres em suas resistências, de modo também conectado às lutas de populações negras e tradicionais contra a exploração, degradação socioambiental e discriminações. Afinal, na luta pela superação do TEC deve-se evitar o risco de naturalizar as explora- ções dita "normais" das relações de trabalho assalariadas bem como outras opressões de gênero, etnia, raça etc. Essas complexas questões uma vez ausentes dos diálogos entre movimentos sindical, organizações neoabolicionistas e movimentos de defesa da saúde dos trabalhadores se tornariam fatores limitantes para o ideal de erradicar o TEC.

\section{Considerações finais}

O artigo destacou alguns desafios da vigilância em saúde do trabalhador para a erradicação do TEC e demonstrou a importância de (a) identificar setores econômicos, regiões e populações afetadas; (b) de aumentar o conhecimento sobre determinantes sociais, riscos e efeitos à saúde das populações escravizadas, a fim de permitir comparações entre regiões e outras populações trabalhadoras; (c) e de fortalecer ações e serviços em saúde do trabalhador para ampliar a participação desse setor nas ações antiescravistas.

Nossa intenção não foi desenhar um plano operacional para a VISAT lidar com o trabalho escravo, mas chamar a atenção para seu papel e potencial teórico-prático para romper ciclos de escravização de trabalhadores.

Os desafios aqui referidos são limitados e não abarcam a complexidade da demanda que a existência dessas relações de trabalho coloca para a VISAT. Entretanto, com espírito crítico podese ampliar o horizonte e melhor compreender a tarefa exigida do campo das relações saúde-trabalho-ambiente a fim de vislumbrar alternativas concretas para fortalecer a luta pela emancipação dos trabalhadores, especialmente nessa conjuntura sociopolítica desfavorável da realidade brasileira.

\section{Colaboradores}

LHC Leão contribuiu na concepção, delineamento, análise e interpretação dos dados. P Siebert, A Trautrims, V Zanin e K Bales contribuíram na redação do artigo e sua revisão crítica bem como aprovação da versão a ser publicada. 


\section{Agradecimentos}

Ao Departamento de Filosofia, Sociologia, Pedagogia e Psicologia Aplicada da Universidade de Padova, Itália e ao Right Lab da Universidade de Nottingham, Reino Unido, por receberem o professor Luís Leão como pesquisador visitante durante o ano 2019 e a Don Roberto Ravazzolo do Centro Universitario Padovano pelo suporte para a pesquisa em Padova.

\section{Referências}

1. Brace L, Davidson OC. Slavery and the revival of anti-slavery activism. In: Brace L, Davidson OC, organizadores. Revisiting Slavery and AntiSlavery. Toward a critical analysis. Palgrave: Macmillan; 2018. p. 3-34.

2. Stewart JB, Swanson E. Getting Beyond Chattle Slavery. In: Stewart JB, Swanson E, organizadores $\mathrm{Hu}$ man Bondage and Abolition. New Histories of Past and Present Slaveries. Cambridge: University press; 2018. p. 1- 37.

3. Allain J, Crane A, Lebaron G, Behbahani L. Forced labour's business models and supply chains. Belfast: Queen's University Belfast; 3013.

4. Gold S, Trautrims A, Trodd Z. Modern slavery challances to supply chain managemant. Supply chain management: an international journal 2015; 20(5):485-494.

5. Bales K. Ending Slavery. How we free today's slaves. London: University of California Press; 2007.

6. Fairchild AL, Haghdoost AA, Bayer R, Selgelid MJ, Dawson A, Saxena A. Ethics of public health surveillance: new guidelines. The lancet Pub Health 2017; 2(8):348-e349.

7. Benach J, Puig-Barrachina V, Vives A, Tarafa G, Muntaner $\mathrm{C}$. The challenge of monitoring employment-related health inequalities. J Epidemiol Community Health 2012; 66(12):1085-1087.

8. Zimmerman C, Kiss L, Hossain M, Watts C. Trafficking in persons: a health concern? Cien Saude Colet 2009; 14(4):1029-1035.

9. Such E, Walton E, Bonvoisin T, Stoklosa H. Modern Slavery: a global public health concern. BMJ 2019; 364:i838.

10. Paula King P, Blaiklock A, Stringer C, Amaranathan J, McLean M. Slavery in New Zealand: What is the role of the health sector? The New Zealand Med Journal 2017; 130(1463):63-69.

11. O'Callaghan MG. The Health Care Professional as a Modern Abolitionist. Perm J Spring 2012; 16(2):67-69.

12. Abas M, Ostrovschi NV, Prince M, Gorceag VI, Trigub C, Oram S. Risk factors for mental disorders in women survivors of human trafficking: a historical cohort study. BMC Psychiatry; 13(204):1-11.

13. Kiss L, Pocock NS, Naisanguansri V. Health of men, women, and children in post-tracking services in Cambodia, Thailand, and Vietnam: an observational cross-sectional study. Lancet Glob Health 2015; 3:e154-61.

14. Ibrahim H, Ertl V, Catani C, Ismail AA, Neuner F. Trauma and perceived social rejection among Yazidi women and girls who survived enslavement and genocide. BMC Medicine 2018; 16(154):1-11.

15. Jaeger WW. Paideia. A formação do homem grego. Sao Paulo: Martins Fontes; 1986.

16. McCandless P. Slavery, Disease and Suffering in the Southern Lowcountry. Cambridge: University Press; 2011.

17. Mustakeen SM. Slavery at Sea. Terror, Sex and Sickness in the Middle Passage. Chicago: University of Illinois Press; 2016.

18. Fett S. Working Cures. Healing, Health and Power on Southern Slave Plantations. London: University of North Carolina Press; 2002. 
19. Eyerman R. Cultural Trauma: Slavery and the Formation of African American Identity. Cambrige: University Press; 2001.

20. Zimmerman C, Kiss L. Human trafficking and exploitation: A global health concern. PLoS Med 2017; 14(11): e1002437.

21. Turner-Moss E, Zimmerman C, Howard LM, Oram S. Labour Exploitation and Health: A Case Series of Men and Women Seeking Post-Trafficking Services. $J$ Immigrant Minority Health 2014; 16(3):473-480.

22. Bales K. Blood and Earth: modern slavery, ecocide, and the secret to saving the world. New York: Spiegel and Grau; 2016.

23. Bales K, Trodd Z, Williamson AK. The suffering of multitudes: modern's slavery health risks and consequence. In: Bales K, Trodd Z, organizadores. Modern Slavery. Beginners guides. Oxford: Oneworld Publications; 2009. p. 124-144.

24. Brass T. Unfree labour as primitive accumulation? $\mathrm{Ca}$ pital and Class 2010; 35(1):23-38.

25. Patterson O. Slavery and Social Death. A comparative Study. Havard University Press: 1982.

26. Elkins SM. Slavery: A Problem in American Institutional and Intellectual Life. Chicago: The University of Chicago Press; 1959.

27. Brasil. Lei $n^{\circ} 10.803$, de 11 de dezembro de 2003. Altera o art. 149 do Decreto Lei no 2.848, de 7 de dezembro de 1940 Código Penal, para estabelecer penas ao crime nele tipificado e indicar as hipóteses em que se configura condição análoga à de escravo. Brasília (DF); 2003.

28. Brasil. Ministério da Saúde (MS). Portaria n 3.120, de 01 de Julho de 1998. Aprova a Instrução Normativa de Vigilância em Saúde do Trabalhador no SUS. Brasília: MS; 1998. Diário Oficial da União, 1998. 14 jul.

29. Todres J. Moving Upstream: The Merits of a Public Health Law Approach to Human Trafficking N.C. L. Rev 2011; 89(2):447-506.

30. Zimmerman C, Hossain M, Watts C. Human trafficking and health: A conceptual model to inform policy, intervention and research. Soc Sci Med 2011; 73(2):327-335.

31. Plataforma SmartLab. Observatório da Erradicação do Trabalho Escravo e do Tráfico de Pessoas. [acessado 2020 mar 29]. Disponível em: http://observatorioescravo.mpt.mp.br

32. Rioux S, Lebaron G, Verovšek PJ. Capitalism and unfree labor: a review of Marxist perspectives on modern slavery. Review Intern Political Econ 2019:1-24.

33. International Labour Organization and Walk Free Foundation. Global estimates of modern slavery: forced labour and forced marriage. Geneva: International Labour Office; 2017.

34. Lebaron G, Howard N, Thibos C, Kyritsis P. Confronting root causes: forced labour in global supply chains. Sheffield: OpenDemocracy, University of Sheffield; 2018.

35. Langthaler E, Schübler E. Commodity Studies with Polanyi: Disembedding and Re-Embedding Labour and Land in Contemporary Capitalism. Österreichische Soziologie 2019; 44(2):209-223.
36. Laurell AC, Noriega M. Processo de produção e saúde. Trabalho e desgaste operário. São Paulo: Cebes: 1989.

37. Bales K. Fletcher Le, Stover E, Lize S, Shigekane R. Hidden slaves. Forced labor in the United States. Berkeley: Human Rights Center University of California; 2004.

38. Lancman S, Sznelman LI, organizadores. Christophe Dejours: da Psicopatologia à Psicodinâmica do trabalho. Rio de Janeiro: Editora Fiocruz; 2004.

39. Karasek RA, Theorell T. Healthy Work. New York: Basic Books; 1990.
Artigo apresentado em 24/04/2020

Aprovado em 28/07/2021

Versão final apresentada em 30/07/2021

Editores-chefes: Romeu Gomes, Antônio Augusto Moura da Silva 
